\title{
Status Konservasi Burung Pada Resort Coban Trisula Dan Blok Ireng-Ireng, Taman Nasional Bromo Tengger Semeru
}

\section{Conservation Status Of Birds In Coban Trisula Resort And Ireng-Ireng Block, Bromo Tengger Semeru National Park}

\author{
Boni Herdiawan $^{1}$, Muhammad Musthofa Mubarok ${ }^{1}$, Reni Ambarwati ${ }^{1}$, \\ Koestriadi Nugra Prasetya ${ }^{2}$ \\ ${ }^{1}$ Jurusan Biologi, Fakultas Matematika dan Ilmu Pengetahuan Alam, Universitas Negeri Surabaya \\ ${ }^{2}$ Taman Nasional Bromo Tengger Semeru \\ *Korespondensi : boniherdiawan@mhs.unesa.ac.id
}

\begin{abstract}
Abstrak
Taman Nasional Bromo Tengger Semeru merupakan salah satu kawasan konservasi di Jawa Timur. Taman Nasional Bromo Tengger Semeru merupakan kawasan dengan keragaman hayati yang tinggi, salah satunya adalah burung. Resort Coban Trisula dan Blok Ireng-Ireng diketahui merupakan kawasan dengan keragaman burung yang tinggi di Taman Nasional Bromo Tengger Semeru. Penelitian ini bertujuan untuk mengidentifikasi status konservasi burung di Resort Coban Trisula dan Blok Ireng-Ireng, Taman Nasional Bromo Tengger Semeru. Penelitian ini menggunakan metode pendekatan birdwatching dengan mengacu pada IUCN Red List, CITES Appendix, Peraturan Pemerintah Nomor 7 Tahun 1999 dan Peraturan Menteri LHK Nomor 106 Tahun 2018 sebagai database status konservasi burung yang teridentifikasi. Hasil penelitian menunjukkan bahwa dari 62 jenis yang terobservasi di kawasan Resort Coban Trisula dan Blok Ireng-Ireng, terdapat 16 jenis yang memiliki status konservasi diatas Least Concern menurut IUCN, CITES dan Peraturan Menteri LHK Nomor 106 Tahun 2018. Adanya burung-burung yang dilindungi dan memiliki status konservasi yang penting menguatkan peran kawasan Taman Nasional Bromo Tengger Semeru sebagai kawasan konservasi. Terdapat tujuh jenis burung di atas status Least Concern menurut IUCN yaitu tiga jenis berstatus Near Threatened, tiga jenis berstatus Vulnurable, dan satu jenis berstatus Endangered. Delapan jenis yang masuk pada CITES Appendix dengan rincian satu jenis tergolong Appendix I dan tujuh jenis tergolong Appendix II. 15 jenis dilindungi oleh Peraturan Menteri LHK Nomor 106 Tahun 2018.
\end{abstract}

Kata Kunci : Konservasi, Burung, Taman Nasional Bromo Tengger Semeru

\begin{abstract}
Bromo Tengger Semeru National Park is one of the conservation area in East Java. Bromo Tengger Semeru National Park have a high nuber of biodiversity, example birds. Coban Trisula Resort and Ireng-Ireng Block were area which have high diversity of birds. This study aimed to identify the conservation status of birds at Coban Trisula Resort and Ireng-Ireng Block, Bromo Tengger Semeru National Park. This study used a birdwatching approach using IUCN, CITES, and Government Regulation Number 7 of 1999 and the appendix based on Minister of Environmental and Foresty Regulation Number 106 of 2018 as a database of the identification of conservation status of birds. The results showed that among 62 species observed at Coban Trisula Resort and Ireng-Ireng Block, there were 16 species that had conservation status above the Least Concern Status according to IUCN, CITES and Minister of Environmental and Foresty Regulation Number 106 of 2018. The presence of protected birds and birds which have important conservation status strengthen role of Bromo Tengger Semeru National Park as conservation area. Where there were seven species above the Least Concern status according to IUCN, three species were Near Threatened, three species were Vulnerable and one species as Endangered. Eight species included in CITES Appendix, more details were one species was Appendix I and seven species were Appendix II. 15 Species were protected by Minister of Environmental and Forestry Regulation Number 106 of 2018.
\end{abstract}

Keywords: Conservation, Birds, Bromo Tengger Semeru National Park 


\section{PENDAHULUAN}

Taman Nasional Bromo Tengger Semeru adalah salah satu taman nasional yang berlokasi di Jawa Timur dan dihimpit oleh empat kabupaten, yaitu Malang, Pasuruan, Probolinggo, dan Lumajang. Taman nasional ini memiliki rentang elevasi yang lebar, dari 750 mdpl hingga 3676 mdpl. Akibatnya, Taman Nasional Bromo Tengger Semeru memiliki jenis habitat yang beragam serta jenis flora dan fauna yang beragam pula, menyesuaikan dengan kondisi habitat. Taman Nasional Bromo Tengger Semeru ini merupakan kawasan konservasi sebagai benteng terakhir keanekaragaman tropis, yaitu kawasan perlindungan bagi keanekaragaman hayati termasuk flora fauna yang ada di dalamnya (BBTNBTS, 2013).

Burung merupakan salah satu fauna yang umum dijumpai di Taman Nasional Bromo Tengger Semeru. Burung di Taman Nasional Bromo Tengger Semeru tersebar di seluruh habitat yang ada. Berdasarkan observasi yang telah dilakukan oleh Prasetya dan Siswoyo (2017) terdapat 183 jenis burung yang tercatat di Taman Nasional Bromo Tengger Semeru. Menurut penelitian Iqbal, dkk., (2015) pada kawasan Resort Coban Trisula Taman Nasional Bromo Tengger Semeru, memiliki pola persebaran spasial burung yang berada pada pola agregasi. Diantara melimpahnya jenis-jenis burung tersebut, terdapat jenis-jenis migran dan penetap serta dilindungi oleh Undang-Undang serta berada pada status terancam punah (Prasetya dan Siswoyo, 2017).

Namun akhir-akhir ini burung menjadi pusat perhatian karena maraknya perdagangan liar serta perburuan liar yang dapat berefek pada keseimbangan ekosistem (Iskandar, 2014). Dampak dari perdagangan liar dan perburuan liar tersebut adalah menurunya populasi burung tertentu sehingga dapat berakibat jumlahnya di alam terus menurun. Untuk mencegah dan melindungi burung-burung tersebut, maka dibuat peraturan oleh pemerintah Indonesia yang tertuang dalam Peraturan Pemerintah No. 7 tahun 1999, memuat jenis-jenis flora dan fauna yang dilindungi yang kini lampirannya diperbaharui dalam Peraturan Menteri Lingkungan Hidup dan Kehutanan (LHK) Nomor 106 Tahun 2018. Peraturan Pemerintah tersebut mengacu pada UU No. 5 Tahun 1990. Selain itu pada level internasional dibentuk CITES (Convention on International Trade in Endangered Species of Wild Fauna and Flora) serta IUCN. CITES yaitu perjanjian yang mengatur perdagangan hayati secara internasional (Hutton, dkk. 2000). Sedangkan IUCN merupakan organisasi yang bergerak dalam konservasi sumber daya alam yang memiliki penilaian atas status konservasi suatu biota.

Resort Coban Trisula dan merupakan resort pengelolaan taman nasional di Taman Nasional Bromo Tengger Semeru. Blok Ireng-Ireng Merupakan salah satu kawasan bagian 
dari Resort Seroja.. Keduanya merupakan spot terbaik untuk mengamati burung di Taman Nasional Bromo Tengger Semeru. Penelitian ini bertujuan untuk mengetahui status konservasi burung pada Resort Coban Trisula dan Blok Ireng-Ireng.

\section{METODE PENELITIAN}

Penelitian ini merupakan penelitian observasi dengan mengacu pada literasi tertentu. Penelitian dilakukan dalam rentang 8 Januari 2018 hingga 8 Februari 2018. Observasi dilakukan dengan pendekatan Birdwatching pada Resort Coban Trisula dan Blok Ireng-Ireng (Gambar 1.)

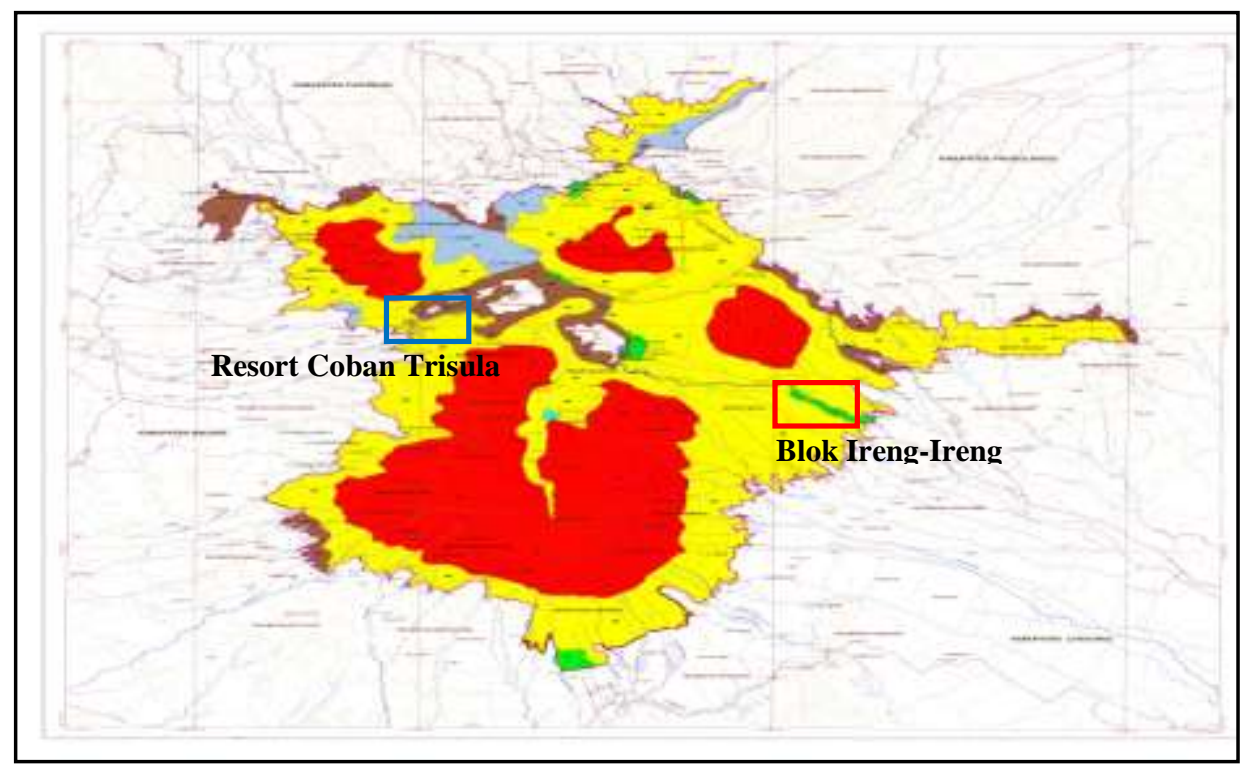

Gambar 1. Lokasi Resort Coban Trisula dan Blok Ireng-Ireng

Metode yang digunakan adalah line transect, yaitu dengan melakukan pengamatan burung pada sepanjang jalur, pada penelitian ini yaitu jalan raya. Pengamatan burung dilakukan pada pukul 06.00 hingga pukul 10.00. Merujuk Rusmendro (2009) bahwa burung lebih banyak ditemui saat pagi hari. Alat yang dibutuhkan antara lain teropong binocular, kamera Nikon L820, buku identifikasi burung Sumatera, Jawa, Bali dan Kalimantan (MacKinnon, dkk., 2010) serta buku burung-burung di Taman Nasional Bromo Tengger Semeru (Prasetya dan Siswoyo, 2017) dan alat tulis. Setiap burung yang dijumpai, diidentifikasi jenisnya kemudian dicatat waktu perjumpaan, jumlah dan aktivitasnya. Data perjumpaan burung tersebut kemudian diringkas, lalu dihitung indeks kemelimpahannya menggunakan indeks kemelimpahan. Kemudian setiap jenis dikaitkan statusnya menurut PP Nomor 7 Tahun 1999 serta Peraturan Menteri LHK Nomor 106 Tahun 2018, CITES pada 
http://checklist.cites.org/\#/en, IUCN pada http://www.iucnredlist.org/, serta status huni pada Prasetya dan Siswoyo (2017).

Indeks Kemelimpahan :

$D 1=\frac{n i}{N} \times 100 \%$

Keterangan:

Di: Indeks kemelimpahan jenis burung i

$\mathrm{Ni}$ : jumlah burung jenis $\mathrm{i}$

$\mathrm{N}$ : jumlah total semua burung yang teramati

\section{HASIL DAN PEMBAHASAN}

Berdasarkan hasil observasi pada Resort Coban Trisula dan Blok Ireng-Ireng, teramati 52 jenis burung dari 28 famili di Resort Coban Trisula, serta 31 jenis dari 24 famili di kawasan Blok Ireng-Ireng. Total jenis yang diamati dari kedua lokasi tersebut adalah 62 spesies dengan rincian 10 jenis hanya terdapat di Blok Ireng-Ireng, 32 jenis hanya terdapat di Resort Coban Trisula dan 20 jenis ada di kedua tempat tersebut (lampiran). Jumlah spesies yang ditemukan masih mencakup sepertiga jumlah list spesies burung menurut Prasetya dan Siswoyo (2017). Bila dibandingkan dengan penelitian Dewi, dkk (2007) di tipe habitat yang sama yaitu hutan primer, jumlah spesies yang ditemukan di Resort Coban Trisula dan Blok Ireng-Ireng sama dengan jumlah spesies burung yang ditemukan di habitat hutan primer TN Gunung Ciremai.

\section{Kemelimpahan Burung}

Kemelimpahan burung yang ada dianalisis menggunakan parameter kerapatan relatif. Burung dinyatakan dominan apabila kerapatan relatif $>5 \%$, subdominan apabila kerapatan relatif antara 2\%-5\% dan nondominan atau jarang bila kerapatan relatif < $2 \%$ (Krebs, 1989). Pada Resort Coban Trisula diketahui terdapat empat jenis yang memiliki indeks kemelimpahan lebih dari 5\% yaitu Elang Hitam (Ictinaetus malaiensis) sebesar 5\%, Walik Kepala Ungu (Ptilinopus Phorphyreus) sebesar 7.3\%, Walet Linchi (Collocalia linchi) 9.6\%, dan Sepah Gunung (Pericrocotus miniatus) sebesar 5,7\%. Sementara pada Blok Ireng-Ireng terdapat 5 jenis yang memiliki indeks kemelimpahan lebih dari 5\%, yaitu Sepah Gunung (Pericrocotus miniatus) sebesar 13,2\%, Serindit Jawa (Loriculus pusillus) sebesar 7.4\%, Munguk Loreng (Sitta azurea) sebesar 10.7\%, Walet Linchi (Collacolia linchi) dan Opior Jawa (Lophozosterops javanicus) sebesar 10.7\%. 
Pada spesies dominan Resort Coban Trisula tidak semua merupakan spesies dominan juga pada Blok Ireng-Ireng, begitu juga spesies dominan pada Blok Ireng-Ireng tidak semua juga merupakan spesies dominan di Resort Coban Trisula. Spesies yang merupakan dominan yang sama antara kedua kawasan tersebut adalah Pericrocotus miniatus serta Collocalia Linchi. Pericrocotus miniatus sering kali pada resort Coban Trisula terbang berkelompok dari pohon satu ke pohon lain, begitu juga yang terlihat di Blok Ireng-Ireng. Menurut Syafrudin (2011) burung dengan sifat suka mengelompok biasanya akan memiliki kemelimpahan yang lebih tinggi di suatu kawasan. Sedangkan Collocalia linchi sering kali terlihat terbang kearah yang tidak beraturan di kawasan Resort Coban Trisula dan Blok Ireng-Ireng. Sesuai dengan Wisnubudi (2009) yang dalam penelitiannya Collocalia linchi teramati pada empat strata pohon yang berbeda dan juga dalam Rahayuningsih, dkk (2010) serta Wulandari dan Kuntjoro (2019) yang dalam penelitiannya menyebutkan bahwa Collocalia linchi merupakan spesies dengan kemelimpahan tinggi dan tersebar di berbagai tipe habitat.

Beberapa spesies dominan diketahui hanya ada di Resort Coban Trisula, yaitu Ictinaetus malaiensis dan Ptilinopus phorphyreus. Ictinaetus malaiensis sering kali terlihat terbang menuju dan dari daerah tepian perbatasan Taman Nasional untuk mencari makan di ladang masyarakat. Sering kali Ictinaetus malaiensis terpantau terbang membawa mangsa tikus ketika terbang menuju arah Taman Nasional. Ptilinopus phorphyreus terpantau di Resort Coban Trisula sedang mencari makan pada pohon-pohon yang sedang berbuah. Ptilinopus phorphyreus terpantau melimpah karena bulan Januari-Februari merupakan masa berbuah beberapa pohon buah di Resort Coban Trisula, sebagaimana dinyatakan oleh Fitri, dkk (2016) bahwa keragaman burung dipengaruhi oleh faktor kelimpahan buah-buahan di hutan.

Beberapa spesies dominan diketahui hanya ada di Blok Ireng-Ireng, yaitu Loriculusu pusillus, Sitta azurea dan Lophozosterops javanicus. Loriculus pusillus terpantau hanya di Blok Ireng-Ireng sedang mencari makan secara berkelompok pada pohon-pohon yang memiliki kelebatan dan ketinggian yang tinggi serta berumur tua, hal ini sesuai dengan penelitian Widodo (2009) Loriculus pusillus teramati memiliki kelimpahan yang tinggi di kawasan TN Alas Purwo, menandakan spesies tersebut berkembang dengan baik di kawasan Blok Ireng-Ireng. Sitta azurea terpantau di kedua kawasan, namun untuk Blok Ireng-Ireng memiliki populasi yang lebih banyak. Sitta azurea terpantau di Ireng-Ireng sedang mencari makan pada tajuk pohon dengan ketinggian sedang hingga tinggi, seringkali ditemukan di 
cabang-cabang batang dengan perilakunya yang khas, yaitu selalu bergerak dan seringkali berjalan melawan arah gravitasi. Lophozosterops javanicus ditemukan di kedua kawasan, namun memiliki populasi lebih banyak pada Blok Ireng-Ireng. Selama penelitian, Lophozosterops javanicus ditemukan pada pohon-pohon bertajuk tinggi sedang bertengger ataupun mencari makan.

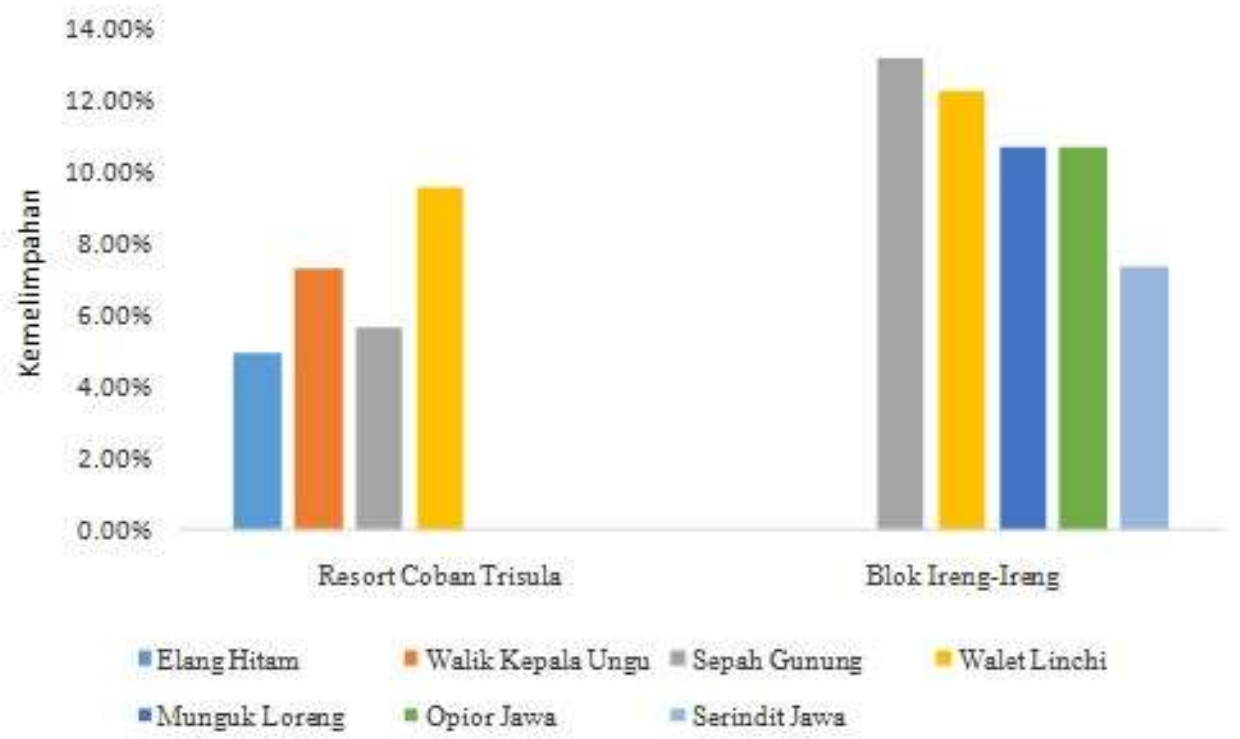

Gambar 1. Perbandingan Jenis Pada Resort Coban Trisula dan Blok Ireng-Ireng yang Memiliki kelimpahan $>5 \%$

Burung memiliki perbedaan karakter setiap spesies dalam beradaptasi dengan lingkungan sehingga memiliki pesebaran yang berbeda-beda pada setiap tipe habitat (Soendjoto, dkk. 2016). Menurut Kuswanda (2010), komposisi tumbuhan berpengaruh pada populasi burung sekitar 94,3\%, hal ini dikarenakan pada tumbuhan-tumbuhan tersebutlah sebagaian besar burung beraktivitas. Pada keenam jenis burung yang memiliki kemelimpahan tertinggi tersebut kecuali Ictinaetus malaiensis, selama observasi sering kali ditemukan pada pohon yang memiliki jenis yang sama. Widodo (2009) juga menyatakan bahwa 37,2\% burung menggunakan tumbuhan yang sama sebagai sumber pakan dan beraktivitas. Selain itu menurut Azis (2014), arsitektur pohon-pohon di suatu kawasan seperti percabangan dan naungan akan memengaruhi kehadiran burung sehingga jenis tumbuhan mempengaruhi kemelimpahan dari populasi burung. Selama pengamatan, ditemukan spesies migran seperti sikatan biru putih dan sikatan burik. Hal ini menurut Widodo (2014) mengindikasikan suatu kawasan memiliki nilai penting sebagai kawasan konservasi burung. 


\section{Status Konservasi}

Berdasarkan hasil observasi dan dikaitkan dengan status konservasinya menurut IUCN, Resort Coban Trisula memiliki enam jenis burung yang status konservasinya diatas Least Concern. Elang jawa (Nisaetus bartelsi) berstatus Endangered; Takur tulung tumpuk (Psilopogon javensis) berstatus Near Threatened; Serindit jawa (Loriculus pusillus) berstatus Near Threatened; Julang emas (Rhyticeros undulates) dan Cica daun besar (Chloropsis sonnerati) berstatus Vulnurable; serta Cica daun sayap biru (Chloropsis cochinchinensis) berstatus Near Threatened. Sementara itu pada Blok Ireng-Ireng terdapat dua jenis burung yang memiliki status konservasi di atas Least Concern. Pelatuk jawa (Chrysocolaptes strictus) berstatus Vulnerable, dan Serindit jawa (Loriculus pusillus) berstatus Near Threatened.

Elang jawa (Nisaetus bartelsi) berstatus Endangered dikarenakan populasinya terus menurun akibat kualitas habitat yang berkurang hingga menyisakan kurang lebih 300-500 spesies dewasa (Birdlife International, 2017) serta diakibatkan meningkatnya perdagangan Elang jawa pada masyarakat (Nijman, dkk, 2009). Lambatnya reproduksi Elang jawa diakibatkan siklus reproduksinya yang bergantung pada kondisi habitat serta iklim (Nijman, dkk., 2000).

Terdapat tiga spesies burung yang memiliki status konservasi Vulnerable, yaitu Pelatuk jawa (Chrysocolaptes strictus), Julang emas (Rhyticeros undulates) dan Cica daun besar (Chloropsis sonnerati). Pelatuk Jawa (Chrysocolaptes strictus) berstatus Vulnerable dikarenakan popoulasinya yang terus turun diakibatkan hilangnya habitat. Selain itu Pelatuk jawa sulit ditemukan pada daerah yang luas pada daerah endemiknya yaitu Jawa (Birdlife International, 2016). Julang Emas (Rhyticeros undulates) berstatus Vulnurable dikarenakan menurunnya populasi akibat kerusakan hutan serta alih fungsi lahan dan juga perburuan (Birdlife International, 2018). Cica daun besar (Chloropsis sonnerati) berstatus Vulnurable dikarenakan menurunnya populasi di alam akibat tingginya perburuan untuk diperdagangkan, karena spesies ini memiliki permintaan tinggi terutama untuk digunakan dalam kompetisi kicau (Birdlife International, 2016).

Terdapat tiga spesies burung yang memiliki status konservasi Near Threatened, yaitu Takur tulung tumpuk (Psilopogon javensis), Serindit jawa (Loriculus pusillus), dan Cica daun sayap biru (Chloropsis cochinchinensis). Takur tulung tumpuk (Psilopogon javensis) berstatus Near Threatened karena popoulasinya yang semakin menurun dan sulit ditemukan 
apada area yang luas karena adanya kerusakan hutan, penebangan serta peralihan fungsi lahan (Birdlife International, 2017). Serindit jawa (Loriculus pusillus) berstatus Near Threatened dikarenakan populasinya yang terus menurun karena perburuan liar serta kerusakan hutan di dataran rendah (Birdlife International, 2016). Cica daun sayap biru (Chloropsis cochinchinensis) berstatus Near Threatened karena maraknya perburuan liar karena spesies ini termasuk burung yang diperdagangkan (Birdlife International, 2016).

Berdasarkan penelusuran pustaka didapatkan penyebab menurunnya populasi spesiesspesies yang memiliki status konservasi dibawah Least Concern diakibatkan rusaknya habitat burung-burung serta perdagangan liar. Habitat burung seperti hutan primer kini banyak dialih fungsikan, padahal menurut Sodhi, dkk (2005) hutan primer memiliki nilai konservasi tertinggi untuk burung. Pengalihan fungsian lahan hutan menyebabkan terjadi fragmentasi habitat yang menyebabkan banyak spesies seperti raptor terancam punah (Thiollay, dkk., 1988). Perburuan dan perdagangan burung secara liar juga merupakan ancaman serius dalam konservasi burung di Indonesia (Pangau-Adam dan Noske, 2010) karena kebanyakan praktiknya mengambil langsung dari alam.

Untuk mendukung perlindungan flora fauna dan pengawetannya, Pemerintah Indonesia mengesahkan Peraturan Pemerintah nomor tujuh tahun 1999 yang memuat daftar flora fauna Indonesia yang dilindungi, kemudian daftar jenis-jenisnya di perbarui melalui Peraturan Menteri LHK Nomor 106 Tahun 2018. Beberapa jenis burung yang terdapat di Resort Coban Trisula dan Blok Ireng-Ireng masuk dalam daftar tersebut (Prasetya dan Siswoyo, 2017). Peraturan Pemerintah Nomor 7 Tahun 1999 tersebut melindungi burung yang bersifat endemik untuk suatu daerah (penyebaran terbatas), berpopulasi kecil, serta jumlah individu di alam menurun tajam (Sukmantoro, dkk. 2007). Diketahui terdapat 13 jenis burung di Resort Coban Trisula dan enam jenis burung di Blok Ireng-Ireng yang dilindungi menurut Peraturan Menteri LHK Nomor 106 Tahun 2018.

Indonesia telah meratifikasi CITES melalui Keputusan Presiden Nomor 43 Tahun 1978. Pada CITES terdapat tiga golongan Appendix, yaitu Appendix I mengatur bahwa seluruh jenis flora fauna yang masuk di dalam daftar ini dilarang dalam segala bentuk perdagangan internasional; Appendix II mengatur perdagangan jenis flora fauna yang tidak segera terancam kepunahan, namun memiliki potensi besar menuju kepunahan bila tidak dikontrol; dan Appendix III mengatur perdagangan flora fauna yang dilindungi di negara tertentu dalam batas-batas habitatnya dengan syarat-syarat tertentu (Bangun, dkk., 2014). Jumlah jenis burung di Resort Coban Trisula dan Blok Ireng-Ireng yang masuk dalam kategori CITES 
berjumlah sama dengan penelitian Hamzati dan Aunurohim (2013) di kawasan Bentang Alam Mbeling bagian barat Flores yaitu sebanyak 8 spesies.

Tabel 1. Daftar Spesies yang dilindungi menurut IUCN, CITES dan Peraturan Menteri LHK No. 106/2018 pada Resort Coban Trisula dan Blok Ireng-Ireng.

\begin{tabular}{llccccc}
\hline \multirow{2}{*}{ No } & \multicolumn{1}{c}{ Spesies } & \multicolumn{2}{c}{ IUCN } & & CITES & \multicolumn{1}{c}{ Peraturan Menteri } \\
LHK No. 106/ 2018
\end{tabular}

Keterangan :

$\mathrm{A}=$ Teramati di Resort Coban Trisula; $\mathrm{B}=$ Teramati di Blok Ireng-Ireng; $\mathrm{I}=$ CITES Apendiks I; II=CITES Apendiks II; v = Dilindungi menurut Peraturan Menteri LHK No. 106/ 2018; NT= Near Threatened (status konservasi IUCN); VU= Vulnurable (status konservasi IUCN); EN= Endangered (status konservasi IUCN)

Berdasarkan kemelimpahan jenis, diketahui terdapat dua jenis burung yang dilindungi memiliki kemelimpahan tinggi diatas 5\%, yaitu Elang hitam dan Serindit jawa. Hal ini menandakan bahwa habitat pada Taman Nasional Bromo Tengger Semeru mendukung kehidupan burung-burung yang dilindungi. Selain itu pada observasi yang dilakukan Prasetya dan Siswoyo (2017) telah ditemukan sarang dari Elang jawa sehingga kawasan TN Bromo Tengger Semeru memiliki nilai penting dalam perkembang biakan spesies tersebut.

Jenis-jenis yang dilindungi tersebut diketahui semuanya adalah jenis penetap sehingga perlu adanya upaya konservasi secara in-situ dengan mengoptimalkan kawasan-kawasan konservasi (Astirin, 2000). Maka dalam hal ini Taman Nasional Bromo Tengger Semeru sebagai kawasan konservasi perlu melakukan upaya konservasi dalam rangka pelestarian dan pengawetan flora dan fauan yang ada di dalam kawasan, terutama burung-burung yang dilindungi. 


\section{KESIMPULAN}

Berdasarkan hasil penelitian diketahui terdapat 62 jenis burung di Resort Coban Trisula dan Blok Ireng-Ireng. Diantara burung-burung tersebut, terdapat 16 jenis yang memiliki status konservasi pada IUCN, CITES dan Peraturan Menteri LHK No. 106/ 2018. Dengan rincian, tujuh jenis diatas status LC, yaitu satu jenis bersatatus Endangered, tiga jenis Near Threatened, dan tiga jenis berstatus Vulnurable berdasarkan IUCN. Delapan jenis masuk CITES, tujuh jenis Appendix II dan satu jenis Appendix I, serta 15 jenis dilindungi oleh Peraturan Menteri LHK No. 106/ 2018.

\section{REFERENSI}

Astirin, O.P., 2000. Permasalahan pengelolaan keanekaragaman hayati di Indonesia. Biodiversitas, Vol. 1(1); 36-40. DOI: 10.13057/biodiv/d010107

Azis, M.C., Budiarti, T. And Wijaya, S., 2014. Kajian Hubungan Arsitektur Pohon dan Kehadiran Burung di Kampus IPB Dramaga Bogor. Jurnal Arsitektur Lansekap, Vol. 2(1):1-10. DOI: https://doi.org/10.24843/JAL.2016.v02.i01.p01

Bangun, O.V. and Pahlawan, I., 2014. Efektivitas Cites (Convention on International Trade in Endangered Species of Wild Fauna and Flora) Dalam Mengatur Perdagangan Hiu Di Kawasan Coral Triangel (Implementasi Di Indonesia). Jurnal Online Mahasiswa (JOM) Bidang Ilmu Sosial dan Ilmu Politik, Vol. 1(2): 1-12.

BBTNBTS, 2013. Buku Zonasi Taman Nasional Bromo Tengger Semeru. Malang: TNBTS

BirdLife International. 2016. Chloropsis cochinchinensis. The IUCN Red List of Threatened Species 2016: Diunduh pada 23 April 2018. http://dx.doi.org/10.2305/IUCN.UK.20163.RLTS.T103775551A95079615.en

BirdLife International. 2016. Chloropsis sonnerati. The IUCN Red List of Threatened Species 2016. Diunduh $\quad$ pada 23 April 2018. http://dx.doi.org/10.2305/IUCN.UK.20163.RLTS.T22704950A93992403.en

BirdLife International. 2016. Chrysocolaptes strictus. The IUCN Red List of Threatened Species 2016. Diunduh pada 23 April 2018. http://dx.doi.org/10.2305/IUCN.UK.20163.RLTS.T22726560A94925352.en.

BirdLife International. 2016. Loriculus pusillus. The IUCN Red List of Threatened Species 2016. Diunduh pada 23 April 2018.http://dx.doi.org/10.2305/IUCN.UK.20163.RLTS.T22685422A93072296.en.

BirdLife International. 2017. Nisaetus bartelsi (amended version of 2016 assessment). The IUCN Red List of Threatened Species 2017. Diunduh pada 23 April 2018. http://dx.doi.org/10.2305/IUCN.UK.2017-1.RLTS.T22696165A110050373.en.

BirdLife International. 2017. Psilopogon javensis (amended version of 2016 assessment). The IUCN Red List of Threatened Species 2017. Diunduh pada 23 April 2018. http://dx.doi.org/10.2305/IUCN.UK.2017-1.RLTS.T22681622A110591039.en. 
BirdLife International. 2018. Rhyticeros undulatus. The IUCN Red List of Threatened

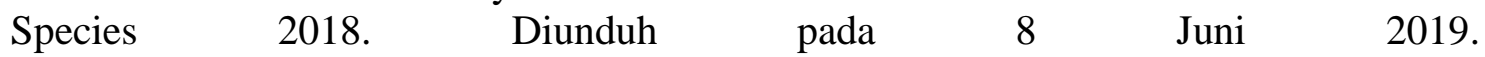
http://dx.doi.org/10.2305/IUCN.UK.20182.RLTS.T22682528A132400385.en

Dewi, R.S., Mulyani, Y.A. and Santosa, Y., 2007. Keanekaragaman Jenis Burung Di Beberapa Tipe Habitat Taman Nasional Gunung Ciremai (Diversity Of Bird Species at Some Habitat Type In Ciremai Mountain National Park). Media Konservasi, Vol. 12(3): 13-15.

Fitri, L.M., Handika, H. and Solina, I.D., 2016. Burung Strata Bawah (Undestory) Di Hutan Pegunungan Taman Nasional Kerinci Seblat (Tnks) Kerinci Jambi. Sainstek: Jurnal Sains dan Teknologi, Vol. 7(1): 82-85.

Hamzati, N.S. and Aunurohim, A., 2013. Keanekaragaman Burung di Beberapa Tipe Habitat di Bentang Alam Mbeliling Bagian Barat, Flores. Jurnal Sains dan Seni ITS, Vol. 2(2): 121-126.

Hutton, J. and Dickson, B. eds., 2000. Endangered species, threatened convention: the past, present and future of CITES, the Convention on International Trade in Endangered Species of Wild Fauna and Flora. London: Earthscan.

Iqbal, K., Gama, Z.P. and Yanuwiadi, B., 2015. Spatial Distribution of Birds in Coban Trisula, Bromo Tengger Semeru National Park. Prosiding International Conference on Global Resource Conservation, Malang. 30 November 2015. Hal. 26-30.

Iskandar, J., 2014. Dilema antara hobi dan bisnis perdagangan burung serta konservasi burung. Chimica et Natura Acta, Vol. 2(3). 180-185.

Krebs, C. J. 1989. Ecological Methodology. Harper \& Row Publisher, New York.

Kuswanda, W., 2010. Pengaruh komposisi tumbuhan terhadap populasi burung di Taman Nasional Batang Gadis, Sumatera Utara. Jurnal Penelitian Hutan dan Konservasi Alam, Vol. 7(2): 193-213.

MacKinnon J, Phillipps K, van Balen B. 2010. Seri Panduan Lapangan Burung-Burung di Sumatera, Jawa, Bali dan Kalimantan. Bogor: Birdlife International-Indonesia Program-Pusat Penelitian dan Pengembangan Biologi LIPI.

Nijman, V., Shepherd, C.R. and van Balen, S., 2009. Declaration of the Javan hawk eagle Spizaetus bartelsi as Indonesia's National Rare Animal impedes conservation of the species. Oryx, Vol. 43(1): 122-128.

Nijman, V., van Balen, S.B. and Sözer, R., 2000. Breeding biology of Javan hawk-eagle Spizaetus bartelsi in West Java, Indonesia. Emu, Vol. 100(2): 125-132.

Pangau-Adam, M. and Noske, R., 2010. Wildlife hunting and bird trade in northern Papua (Irian Jaya), Indonesia. dalam Ethno-ornithology. Birds, Indigenous Peoples, Culture and Society(pp. 73-85). Earthscan London, Washington DC.

Prasetya, K. N. dan Siswoyo, A., 2017. Burung-Burung Taman Nasional Bromo Tengger Semeru. Ediide Infografika. Malang.

Rahayuningsih, M., Purnomo, F.A. and Priyono, B., 2010. Keanekaragaman Burung di Desa Karangasem Kecamatan Wirosari Kabupaten Grobogan Jawa Tengah. Biosaintifika: Journal of Biology \& Biology Education, Vol. 2(2): 82-89. 
Rusmendro, H., 2009. Perbandingan keanekaragaman burung pada pagi dan sore hari di empat tipe habitat di Wilayah Pangandaran, Jawa Barat. Vis Vitalis, Vol. 2(1): 8-16

Sodhi, N.S., Koh, L.P., Prawiradilaga, D.M., Tinulele, I., Putra, D.D. and Tan, T.H.T., 2005. Land use and conservation value for forest birds in Central Sulawesi (Indonesia). Biological Conservation, Vol. 122(4): 547-558.

Soendjoto, M.A., Riefani, M.K. and Zen, M., 2016. Penggunaan Tipe Habitat oleh Avifauna di Lingkungan PT Arutmin Indonesia-NPLCT, Kabupaten Kotabaru, Kalimantan Selatan. Sains \& Matematika, Vol. 3(1): 19-25.

Syafrudin, D., 2011. Keanekaragaman Jenis Burung Pada Beberapa Tipe Habitat di Tambling Wildlife Nature Conservation (TWNC), Taman Nasional Bukit Barisan Selatan Lampung. (Skripsi). Departemen Kehutanan dan Ekowisata, Institut Pertanian Bogor. Bogor

Thiollay, J.M. and Meyburg, B.U., 1988. Forest fragmentation and the conservation of raptors: a survey on the island of Java. Biological Conservation, Vol. 44(4): 229-250.

Widodo, W., 2009. Komparasi keragaman jenis burung-burung di Taman Nasional Baluran dan Alas Purwo pada beberapa tipe habitat. Jurnal Berkala Penelitian Hayati. Vol. (14): 113-124.

Widodo, W., 2014. Populasi dan Pola Sebaran Burung di Hutan Wanawisata Galunggung, Tasikmalaya, Jawa Barat. Biosaintifika: Journal of Biology \& Biology Education, Vol. 6(1): 29-38.

Wisnubudi, G., 2009. Penggunaan strata vegetasi oleh burung di kawasan wisata Taman Nasional Gunung Halimun-Salak. Vis Vitalis, Vol. 2(2): 41-49.

Wulandari, E.Y. and Kuntjoro, S., 2019. Keanekaragaman dan Kelimpahan Jenis Burung di Kawasan Cagar Alam Besowo Gadungan dan sekitarnya Kabupaten Kediri Jawa Timur. Jurnal Riset Biologi dan Aplikasinya, Vol. 1(1):18-25. 
DOI: 10.33373/sim-bio.v8i1.1871

e-ISSN. 2598-6007;p-ISSN. 2301-9417

https://journal.unrika.ac.id/index.php/simbiosajournal

Lampiran 1. Kekayaan jenis burung di Resort Coban Trisula TNBTS

\begin{tabular}{|c|c|c|c|c|c|c|c|}
\hline No. & Famili & Nama Ilmiah & Nama Indonesia & IUCN & CITES & $\begin{array}{c}\text { Peraturan } \\
\text { Menteri } \\
\text { LHK No. } \\
\text { 106/ } 2018 \\
\end{array}$ & $\begin{array}{l}\text { Status } \\
\text { Huni }\end{array}$ \\
\hline \multirow{4}{*}{1} & \multirow{4}{*}{ Accipitridae } & $\begin{array}{l}\text { Ictinaetus } \\
\text { malaiensis }\end{array}$ & Elang Hitam & $\mathrm{LC}$ & II & $\mathrm{v}$ & Penetap \\
\hline & & Nisaetus bartelsi & Elang Jawa & EN & II & $\mathrm{v}$ & Penetap \\
\hline & & Pernis ptilorhyncus & $\begin{array}{l}\text { Elang Sikep Madu } \\
\text { Asia }\end{array}$ & $\mathrm{LC}$ & II & $\mathrm{v}$ & Migran \\
\hline & & Spilornis cheela & Elang Ular Bido & $\mathrm{LC}$ & II & $\mathrm{V}$ & Penetap \\
\hline 2 & Bucerotidae & $\begin{array}{l}\text { Rhyticeros } \\
\text { undulatus }\end{array}$ & Julang Emas & VU & II & $\mathrm{v}$ & Penetap \\
\hline \multirow{2}{*}{3} & \multirow{2}{*}{ Campephagidae } & Coracina larvata & $\begin{array}{ll}\text { Kepudang } & \text { Sungu } \\
\text { Gunung } & \\
\end{array}$ & $\mathrm{LC}$ & - & - & Penetap \\
\hline & & $\begin{array}{l}\text { Pericrocotus } \\
\text { miniatus }\end{array}$ & Sepah Gunung & $\mathrm{LC}$ & - & - & Penetap \\
\hline 4 & Sylviidae & $\begin{array}{l}\text { Orthotomus } \\
\text { cuculatus }\end{array}$ & Cinenen gunung & $\mathrm{LC}$ & - & - & penetap \\
\hline \multirow{2}{*}{5} & \multirow{2}{*}{ Chloropseidae } & $\begin{array}{l}\text { Chloropsis } \\
\text { sonnerati }\end{array}$ & Cica Daun Besar & VU & - & $\mathrm{v}$ & penetap \\
\hline & & $\begin{array}{l}\text { Chloropsis } \\
\text { cochinchinensis }\end{array}$ & $\begin{array}{lll}\text { Cica } & \text { Daun } & \text { Sayap } \\
\text { Biru } & & \\
\end{array}$ & NT & - & $\mathrm{v}$ & penetap \\
\hline 6 & Cisticolidae & Orthotomus sepium & Cinenen Jawa & $\mathrm{LC}$ & - & - & penetap \\
\hline \multirow{4}{*}{7} & \multirow{4}{*}{ Columbidae } & Ducula lacernulata & $\begin{array}{l}\text { Pergam Punggung } \\
\text { Hitam }\end{array}$ & $\mathrm{LC}$ & - & - & penetap \\
\hline & & $\begin{array}{l}\text { Macropygia } \\
\text { ruficeps }\end{array}$ & Uncal Kouran & $\mathrm{LC}$ & - & - & penetap \\
\hline & & $\begin{array}{l}\text { Ptilinopus } \\
\text { porphyreus }\end{array}$ & Walik Kepala Ungu & $\mathrm{LC}$ & - & - & penetap \\
\hline & & Spilopelia chinensis & Tekukur Biasa & $\mathrm{LC}$ & - & - & penetap \\
\hline 8 & Cuculidae & $\begin{array}{l}\text { Phaenicophaeus } \\
\text { curvirostris }\end{array}$ & Kadalan Birah & $\mathrm{LC}$ & - & - & penetap \\
\hline 9 & Dicaediae & $\begin{array}{l}\text { Dicaeum } \\
\text { sanguinolentum }\end{array}$ & Cabai Gunung & $\mathrm{LC}$ & - & - & penetap \\
\hline 10 & Dicruridae & $\begin{array}{l}\text { Dicrurus } \\
\text { leucophaeus }\end{array}$ & Srigunting Kelabu & $\mathrm{LC}$ & - & - & penetap \\
\hline 11 & Estrildidae & $\begin{array}{l}\text { Lonchura } \\
\text { leucogastroides }\end{array}$ & Bondol Jawa & $\mathrm{LC}$ & - & - & penetap \\
\hline 12 & Falconidae & Falco peregrinus & Alap-alap Kawah & $\mathrm{LC}$ & $\mathrm{I}$ & $\mathrm{v}$ & Migran \\
\hline 13 & Laniidae & Lanius schach & Bentet Kelabu & $\mathrm{LC}$ & - & - & penetap \\
\hline \multirow{4}{*}{14} & \multirow{4}{*}{ Megalaimidae } & $\begin{array}{l}\text { Psilopogon } \\
\text { armillaris }\end{array}$ & Takur Tohtor & $\mathrm{LC}$ & - & $\mathrm{v}$ & penetap \\
\hline & & $\begin{array}{l}\text { Psilopogon } \\
\text { haemacephalus } \\
\text { roseus }\end{array}$ & $\begin{array}{l}\text { Takur } \quad \text { Ungkut- } \\
\text { ungkut }\end{array}$ & $\mathrm{LC}$ & - & - & penetap \\
\hline & & Psilopogon javensis & $\begin{array}{ll}\text { Takur } & \text { Tulung } \\
\text { Tumpuk } & \\
\end{array}$ & NT & - & $\mathrm{v}$ & penetap \\
\hline & & $\begin{array}{l}\text { Psilopogon } \\
\text { australis }\end{array}$ & Takur Tenggeret & $\mathrm{LC}$ & - & - & penetap \\
\hline \multirow{7}{*}{15} & \multirow{7}{*}{ Muscicapidae } & $\begin{array}{l}\text { Ficedula } \\
\text { westermanni }\end{array}$ & Sikatan Belang & $\mathrm{LC}$ & - & - & penetap \\
\hline & & $\begin{array}{l}\text { Cyanoptila } \\
\text { cyanomelana }\end{array}$ & Sikatan Biru-Putih & $\mathrm{LC}$ & - & - & Migran \\
\hline & & Ficedula hyperythra & Sikatan Bodoh & $\mathrm{LC}$ & - & - & penetap \\
\hline & & Cyornis unicolor & Sikatan Biru Muda & $\mathrm{LC}$ & - & - & penetap \\
\hline & & $\begin{array}{l}\text { Culicicapa } \\
\text { ceylonensis }\end{array}$ & Sikatan Kepala Abu & $\mathrm{LC}$ & - & - & penetap \\
\hline & & Eumyias indigo & Sikatan Ninon & $\mathrm{LC}$ & - & - & penetap \\
\hline & & Muscicapa & Sikatan Burik & $\mathrm{LC}$ & - & - & Migran \\
\hline
\end{tabular}


SIMBIOSA Vol 8 (1): 70-84, Juli 2019

DOI: 10.33373/sim-bio.v8i1.1871

Herdiawan et al., 2019. Conservation Status Of Birds

\begin{tabular}{|c|c|c|c|c|c|c|c|}
\hline No. & Famili & Nama Ilmiah & Nama Indonesia & IUCN & CITES & $\begin{array}{c}\text { Peraturan } \\
\text { Menteri } \\
\text { LHK No. } \\
106 / 2018\end{array}$ & $\begin{array}{l}\text { Status } \\
\text { Huni }\end{array}$ \\
\hline & & griseisticta & & & & & \\
\hline & & $\begin{array}{l}\text { Myophonus } \\
\text { caeruleus }\end{array}$ & Ciung Batu Siul & $\mathrm{LC}$ & - & - & penetap \\
\hline 16 & Nectariniidae & Aethopyga eximia & $\begin{array}{ll}\text { Burung } & \text { Madu } \\
\text { Gunung } & \end{array}$ & $\mathrm{LC}$ & - & - & penetap \\
\hline 17 & Phylloscopidae & $\begin{array}{l}\text { Seicercus } \\
\text { grammiceps }\end{array}$ & Cikrak Muda & $\mathrm{LC}$ & - & - & penetap \\
\hline \multirow[b]{2}{*}{18} & \multirow[b]{2}{*}{ Picidae } & Dendrocopos analis & Caladi Ulam & $\mathrm{LC}$ & - & - & penetap \\
\hline & & $\begin{array}{l}\text { Dendrocopos } \\
\text { moluccensis }\end{array}$ & Caladi Tilik & $\mathrm{LC}$ & - & - & penetap \\
\hline 19 & Psittacidae & Loriculus pusillus & Serindit Jawa & NT & II & $\mathrm{v}$ & Penetap \\
\hline \multirow{4}{*}{20} & \multirow{4}{*}{ Pycnonotidae } & Ixos virescens & Brinji Gunung & $\mathrm{LC}$ & - & - & Penetap \\
\hline & & $\begin{array}{l}\text { Pycnonotus } \\
\text { bimaculatus }\end{array}$ & Cucak Gunung & $\mathrm{LC}$ & - & - & Penetap \\
\hline & & $\begin{array}{l}\text { Pycnonotus } \\
\text { aurigaster }\end{array}$ & Cucak Kutilang & $\mathrm{LC}$ & - & - & Penetap \\
\hline & & Pycnonotus analis & Merbah Cerukcuk & $\mathrm{LC}$ & - & - & Penetap \\
\hline 21 & Rhipiduridae & Rhipidura euryura & Kipasan Bukit & $\mathrm{LC}$ & - & $\mathrm{V}$ & Penetap \\
\hline \multirow[b]{2}{*}{22} & \multirow{2}{*}{ Sittidae } & Sitta azurea & Munguk Loreng & LC & - & - & Penetap \\
\hline & & Sitta frontalis & Munguk Beledu & $\mathrm{LC}$ & - & - & Penetap \\
\hline 23 & Sturnidae & Aplonis panayensis & Perling Kumbang & $\mathrm{LC}$ & - & - & Penetap \\
\hline \multirow{2}{*}{24} & \multirow{2}{*}{ Timaliidae } & $\begin{array}{l}\text { Cyanoderma } \\
\text { melanothorax }\end{array}$ & Tepus Pipi Perak & $\mathrm{LC}$ & - & - & Penetap \\
\hline & & $\begin{array}{l}\text { Malaconcincla } \\
\text { sepiarium }\end{array}$ & Pelanduk Semak & $\mathrm{LC}$ & - & - & Penetap \\
\hline 25 & Vangidae & $\begin{array}{l}\text { Hemipus } \\
\text { hirundinaceus }\end{array}$ & Jingjing Batu & $\mathrm{LC}$ & - & - & Penetap \\
\hline \multirow{2}{*}{26} & \multirow{2}{*}{ Vireonidae } & $\begin{array}{l}\text { Pteruthius } \\
\text { aenobarbus }\end{array}$ & Ciu Kunyit & $\mathrm{LC}$ & - & - & Penetap \\
\hline & & $\begin{array}{l}\text { Pteruthius } \\
\text { flaviscapis }\end{array}$ & Ciu Besar Jawa & $\mathrm{LC}$ & - & - & Penetap \\
\hline 27 & Zosteropidae & Heleia javanica & Opior Jawa & $\mathrm{LC}$ & - & $\mathrm{v}$ & penetap \\
\hline 28 & Apodidae & Collocalia linchi & Walet Linci & $\mathrm{LC}$ & - & - & penetap \\
\hline
\end{tabular}

Keterangan :

$\mathrm{LC}=$ Least Concern (Status konservasi IUCN) ; NT = Near Threatened (Status konservasi IUCN); VU= Vulnurable(Status konservasi IUCN); EN= Endangered (Status konservasi IUCN); I = CITES Appendix I; II = CITES Appendix II; v = Dilindungi menurut Peraturan Menteri LHK Nomor 106 Tahun 2018

Lampiran 2. Kekayaan jenis burung di Blok Ireng-Ireng TNBTS

\begin{tabular}{|c|c|c|c|c|c|c|c|}
\hline No. & Famili & Nama Ilmiah & Nama Indonesia & Status & CITES & $\begin{array}{c}\text { Peraturan } \\
\text { Menteri } \\
\text { LHK No. } \\
\text { 106/ } 2018 \\
\end{array}$ & $\begin{array}{l}\text { Status } \\
\text { Huni }\end{array}$ \\
\hline & & & & & & & Penetap \\
\hline 1 & Accipitridae & Nisaetus cirrhatus & Elang Brontok & $\mathrm{LC}$ & II & $\mathrm{v}$ & \\
\hline & & & & & & & Penetap \\
\hline 2 & Campephagidae & $\begin{array}{l}\text { Pericrocotus } \\
\text { miniatus }\end{array}$ & Sepah Gunung & $\mathrm{LC}$ & - & - & \\
\hline 3 & Cisticolidae & Orthotomus sepium & Cinenen Jawa & $\mathrm{LC}$ & - & - & Penetap \\
\hline \multirow{2}{*}{4} & \multirow{2}{*}{ Columbidae } & Macropygia unchall & Uncal Loreng & $\mathrm{LC}$ & - & - & Penetap \\
\hline & & Treron griseicauda & Punai Penganten & $\mathrm{LC}$ & - & - & Penetap \\
\hline 5 & Corvidae & Corvus enca & Gagak Hutan & $\mathrm{LC}$ & - & - & Penetap \\
\hline
\end{tabular}


SIMBIOSA, 8 (1): 70-84

Juli 2019

DOI: 10.33373/sim-bio.v8i1.1871

e-ISSN. 2598-6007;p-ISSN. 2301-9417

https://journal.unrika.ac.id/index.php/simbiosajournal

\begin{tabular}{|c|c|c|c|c|c|c|c|}
\hline No. & Famili & Nama Ilmiah & Nama Indonesia & Status & CITES & $\begin{array}{c}\text { Peraturan } \\
\text { Menteri } \\
\text { LHK No. } \\
\text { 106/ 2018 } \\
\end{array}$ & $\begin{array}{l}\text { Status } \\
\text { Huni }\end{array}$ \\
\hline 6 & Cuculidae & $\begin{array}{l}\text { Phaenicophaeus } \\
\text { curvirostris }\end{array}$ & Kadalan Birah & $\mathrm{LC}$ & - & - & Penetap \\
\hline 7 & Dicaediae & $\begin{array}{l}\text { Dicaeum } \\
\text { sanguinolentum }\end{array}$ & Cabai Gunung & $\mathrm{LC}$ & - & - & Penetap \\
\hline 8 & Dicruridae & $\begin{array}{l}\text { Dicrurus } \\
\text { leucophaeus }\end{array}$ & Srigunting Kelabu & $\mathrm{LC}$ & - & - & Penetap \\
\hline 9 & Megalaimidae & $\begin{array}{l}\text { Psilopogon } \\
\text { armillaris }\end{array}$ & Takur Tohtor & $\mathrm{LC}$ & - & $\mathrm{v}$ & Penetap \\
\hline \multirow{4}{*}{10} & \multirow{4}{*}{ Muscicapidae } & $\begin{array}{l}\text { Ficedula } \\
\text { westermanni }\end{array}$ & Sikatan Belang & $\mathrm{LC}$ & - & - & Penetap \\
\hline & & Cyornis unicolor & $\begin{array}{l}\text { Sikatan Biru } \\
\text { Muda }\end{array}$ & $\mathrm{LC}$ & - & - & Migran \\
\hline & & $\begin{array}{l}\text { Culicicapa } \\
\text { ceylonensis }\end{array}$ & $\begin{array}{l}\text { Sikatan Kepala } \\
\text { Abu }\end{array}$ & $\mathrm{LC}$ & - & - & Penetap \\
\hline & & Eumyias indigo & Sikatan Ninon & $\mathrm{LC}$ & - & - & Penetap \\
\hline 11 & Pachycephalidae & $\begin{array}{l}\text { Pachycephala } \\
\text { pectoralis }\end{array}$ & Kancilan Emas & $\mathrm{LC}$ & - & - & Penetap \\
\hline 12 & Pellorneidae & $\begin{array}{l}\text { Pellorneum } \\
\text { pyrrogenys }\end{array}$ & Pelanduk Bukit & $\mathrm{LC}$ & - & - & Penetap \\
\hline 13 & Phylloscopidae & $\begin{array}{l}\text { Seicercus } \\
\text { trivirgatus }\end{array}$ & Cikrak Daun & $\mathrm{LC}$ & - & - & Penetap \\
\hline \multirow[b]{2}{*}{14} & \multirow{2}{*}{ Picidae } & $\begin{array}{l}\text { Hemicircus } \\
\text { concretus }\end{array}$ & Caladi Tikotok & $\mathrm{LC}$ & - & - & Penetap \\
\hline & & $\begin{array}{l}\text { Chrysocolaptes } \\
\text { strictus }\end{array}$ & Pelatuk Jawa & VU & - & - & Penetap \\
\hline 15 & Psittacidae & Loriculus pusillus & Serindit Jawa & NT & II & $\mathrm{v}$ & Penetap \\
\hline \multirow[b]{2}{*}{16} & \multirow[b]{2}{*}{ Pycnonotidae } & Ixos virescens & Brinji Gunung & $\mathrm{LC}$ & - & - & Penetap \\
\hline & & $\begin{array}{l}\text { Pycnonotus } \\
\text { aurigaster }\end{array}$ & Cucak Kutilang & $\mathrm{LC}$ & - & - & Penetap \\
\hline 17 & Rhipiduridae & Rhipidura euryura & Kipasan Bukit & $\mathrm{LC}$ & - & $\mathrm{v}$ & Penetap \\
\hline 18 & Sittidae & Sitta azurea & Munguk Loreng & $\mathrm{LC}$ & - & - & Penetap \\
\hline 19 & Timaliidae & $\begin{array}{l}\text { Cyanoderma } \\
\text { melanothorax }\end{array}$ & Tepus Pipi Perak & $\mathrm{LC}$ & - & - & Penetap \\
\hline 20 & Trogonidae & Harpactes oreskios & Luntur Harimau & $\mathrm{LC}$ & - & $\mathrm{v}$ & Penetap \\
\hline 21 & Vangidae & $\begin{array}{l}\text { Hemipus } \\
\text { hirundinaceus }\end{array}$ & Jingjing Batu & $\mathrm{LC}$ & - & - & Penetap \\
\hline 22 & Vireonidae & $\begin{array}{l}\text { Pteruthius } \\
\text { flaviscapis }\end{array}$ & Ciu Besar Jawa & $\mathrm{LC}$ & - & - & Penetap \\
\hline 23 & Zosteropidae & Heleia javanica & Opior Jawa & $\mathrm{LC}$ & - & $\mathrm{v}$ & Penetap \\
\hline 24 & Apodidae & Collocalia linchi & Walet Linci & $\mathrm{LC}$ & - & - & penetap \\
\hline
\end{tabular}

Keterangan :

$\mathrm{LC}=$ Least Concern (Status konservasi IUCN); NT= Near Threatened (Status konservasi IUCN); VU= Vulnurable (Status konservasi IUCN); EN = Endangered (Status konservasi IUCN); I = CITES Appendix I; II = CITES Appendix II; v = Dilindungi menurut Peraturan Menteri LHK Nomor 106 Tahun 2018 